Research Article

\title{
Effects of Economic Policy Uncertainty on Manufacturing Structural Upgrading: Evidence from China
}

\author{
Renjing Hu (i) and Yanyang Yan \\ College of Finance and Statistics, Hunan University, Changsha 410006, China \\ Correspondence should be addressed to Renjing Hu; renjinghu@hnu.edu.cn
}

Received 20 July 2021; Revised 5 August 2021; Accepted 7 August 2021; Published 13 August 2021

Academic Editor: Daqing Gong

Copyright (c) 2021 Renjing $\mathrm{Hu}$ and Yanyang Yan. This is an open access article distributed under the Creative Commons Attribution License, which permits unrestricted use, distribution, and reproduction in any medium, provided the original work is properly cited.

\begin{abstract}
Manufacturing is one of the drivers of China's growth, realizing structural upgrading is vital to achieve high-quality economic development during periods of economic policy uncertainty. Based on firm-level and province-level panel data from 1997 to 2018 , this paper used a fixed effect panel data model and panel quantile regression model to investigate the effect of economic policy uncertainty on structural upgrading in manufacturing. The findings indicate that the effect of economic policy uncertainty on structural upgrading in manufacturing is significantly positive and great in regions at advanced stages of manufacturing structure. The discussion about the results suggests that the mechanism of economic policy uncertainty affecting structural upgrading in manufacturing operates through pushing the manufacturing industry to implement service transformation strategies along with vertical integration.
\end{abstract}

\section{Introduction}

The global economy has become stagnant in recent decades, and trade conflict is intensifying. The economic policy uncertainty index of China reached its peak during the financial crisis of 2008. China is now facing an excess of domestic production capacity, the accumulation of financial risks, and low quality of economic development along with other difficulties $[1,2]$. To decrease the growing threat in various fields, the government introduced several policies and directions, such as reform of fiscal and tax systems, optimization of fiscal expenditure structures, the One Belt and One Road initiative, etc. These policies and instructions relieved the survival pressure of enterprises and advanced economic development. However, the intensive introduction of policies and regulations brings about numerous uncertainties in the macroeconomy, potentially increasing the operational risk of enterprises. The International Business Questionnaire Survey Report published by Grant Thornton UK L.L.P in 2013 revealed that 40\% of domestic companies considered economic policy uncertainty as the key factor affecting their future development. Optimism for the second quarter was $21 \%$ lower than the first quarter, which is the lowest since 2006. From an international perspective, reports from the Federal Reserve indicate that uncertainty of trading policy hinders global economic development. Hence, economic policy uncertainty is a hazard for global economics.

Manufacturing in China has expanded explosively on the back of the massive demographic dividends, and its global share has increased from $1 \%$ in 1978 to $25 \%$ at present [3]. However, with the shortage of core technologies and the low production rate resulting in structural abnormalities in Chinese manufacturing, the total factor productivity of China is $43 \%$ of that in the United States. Manufacturing is the cornerstone of domestic economic development and fundamental to pushing industry transformation to match the minimum requirements for high-quality economic development $[4,5]$. Since production and operation decisions are highly associated with the macroeconomic environment, it is important to investigate the relationship between economic policy uncertainty and structural upgrading in manufacturing. Studies focusing on the effect of economic policy uncertainty on macroeconomic output are abundant, 
yet few have investigated the correlation between economic policy uncertainty and structural upgrading in manufacturing as well as its effect mechanism. This work makes realistic contributions that could facilitate the development of high-quality Chinese manufacturing, adding to the literature.

There are three general contributions. First, the effect of economic policy uncertainty on manufacturing structural upgrade as well as the effect mechanism itself were investigated. To the best of our knowledge, this is the first study that addresses the influence path of economic policy uncertainty affecting manufacturing structural upgrade, serving as a basis for the transformation and upgrade of Chinese manufacturing in a period of economic policy uncertainty. Second, we adopted a panel quantile regression model that provided robust results and examined the heterogeneous problems linking economic policy uncertainty to manufacturing structural upgrading. A panel quantile regression model outperforms traditional ones by revealing the full scale of the correlation relationship. Third, we empirically analysed the effect mechanism of economic policy uncertainty imposed on manufacturing structural upgrading through the microdatabase and manually collected firm-level data. Specifically, we dissected the transmitting route of the effect, which not only enriches research on economic policy uncertainty, but also clarifies the factors of manufacturing structural upgrading.

The rest of this manuscript is organized as follows: Section 2 presents the literature review, Section 3 presents the theoretical analysis, Section 4 describes the methodologies and data used, Section 5 presents the empirical results, and the last section presents conclusions and suggestions.

\section{Literature Review}

Economic policy uncertainty has increased in recent years, and related studies are abundant. Baker et al. [6] reviewed economic policy uncertainties rooted in the effect of different economic policy decisions adopted at different times; this gave a new perspective for studying economic policy uncertainty. Although most studies consider economic policy uncertainty as a negative factor for economic development [7-10], alternative views have also thrived [11]. Gabauer and Gupta [12] documented that economic policy uncertainty has a positive effect on economic output during downturn periods. Leduc and Liu [13] stated that economic policy uncertainty does not necessarily trigger economic fluctuations; economic policy uncertainty has a stimulating effect on economic output if the policy adjustment can counter economic fluctuations. Mumtaz and Surico [14] discovered a weak link between economic policy uncertainty and industrial output but the former has a significant negative effect on actual sales value.

From a microscopic perspective, most research has consisted of empirical studies on the effect of economic policy uncertainty on firm investment decisions [15-17], innovation behavior [18], and corporate cash holding behavior [19]. Most researchers have concluded that, instead of making decisions immediately, it is more efficient to remain inactive when faced with high economic policy uncertainty. By contrast, Brogaard and Detzel [20] argued that a oneperiod lag of economic policy uncertainty has a stimulating effect on corporate innovation.

The execution of supply-side reform in China resulted in uncertainty for corporations, while providing new inspiration for the upgrading of the manufacturing industry. The Chinese economy has entered a new era of lower economic growth rate than in the preceding years, and the demand for high-quality manufacturing transformation is urgent. How to promote manufacturing upgrade has become a focal point for scholars. Some scholars have investigated the factors influencing manufacturing upgrade [21], while other scholars shifted their attention to the production rate upgrade and documented that the industry upgrade would eventually be reflected on the level of production rates. Kang et al. [22] found that economic policy uncertainty could promote the production rate of the manufacturing industry.

Although existing research throws up many points of view on the correlation between economic policy uncertainty and manufacturing upgrading, it has several limitations. First, there are gaps in the research on the relationship between economic policy uncertainty and manufacturing structural upgrading. Second, current studies have focused on the effect of economic policy uncertainty on a macroscale, ignoring the heterogeneity of different industries. Finally, microstudies on economic policy uncertainty have focused on corporate investment and innovation behavior, and corporate labor force structure changes, while enterprise margins and market margin expansion problems have been neglected. In view of these issues, this study investigated the effect mechanism and heterogeneous problem in the correlation between economic policy uncertainty and manufacturing structural upgrading.

\section{Theory Mechanism and Research Hypothesis}

The impact of economic policy uncertainty on manufacturing structural upgrading mainly occurs through a firm's production and decision behavior. To reduce the operational risk brought about by economic policy uncertainty, firms will adjust their production and management strategies. Figure 1 depicts the effect mechanism of economic policy uncertainty on manufacturing structural upgrading.

A few studies have verified the real option effect of economic policy uncertainty. The core view is to consider corporate decision as an option: when economic policy uncertainty increases, managers would treat the option as a put option. Therefore, compared to executing investment decisions immediately, the company could benefit more from taking no action $[23,24]$. A company's innovation is related to investment behavior. When an economic subject delays their investment, innovation behavior will be suspended, resulting in a lower innovation level [25]. The inhibitory effect of economic policy uncertainty on innovation behavior could weaken the demand for skilled employees in the enterprise, causing redundancy in skilled labor. Meanwhile, economic policy uncertainty has a cash holding effect. 


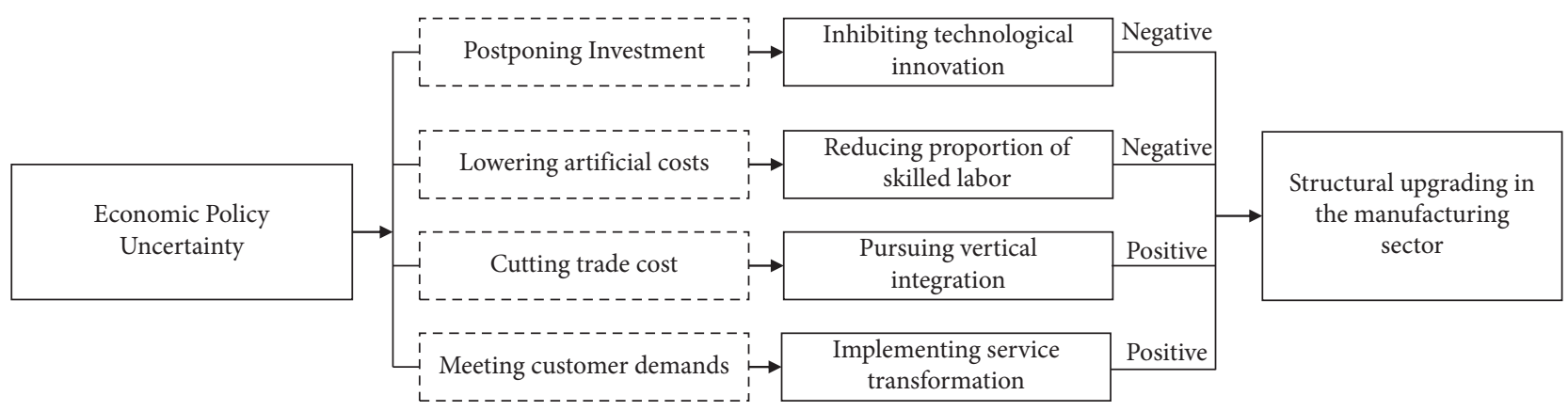

FIGURE 1: Effect mechanism of economic policy uncertainty on manufacturing structural upgrading.

Gervais et al. [26] pointed out that, compared to unskilled workers, skilled workers have higher salaries and companies tend to sack skilled workers in order to cut operating costs during periods of high economic policy uncertainty. A possible explanation is that economic entities with a higher proportion of skilled labor face a greater challenge in resource redistribution. Thus, economic policy uncertainty could potentially affect manufacturing structural upgrading through corporate innovation behavior and the proportion of skilled labor. Accordingly, we propose the following.

3.1. H1a. Economic policy uncertainty could negatively impact manufacturing structural upgrading via postponing technological innovation and reducing the proportion of skilled labor.

From an enterprise margin perspective, the uncertainty of trades in the industrial chain could be magnified by the instability of the market environment during a period of high economic policy uncertainty. Companies tend to carry out a vertical integration strategy to minimize the risk and stabilize operation. Transaction cost theory proposes that asset specificity and business environment uncertainty are the main incentives for a vertical integration strategy. Hence, economic policy uncertainty potentially has the effect of expanding enterprise margins, urging companies to adopt a vertical integration strategy. The enterprise margin expansion effect is more significant in high-end manufacturing as the latter is capital intensive and leads to higher asset specificity.

Vertical integration affects enterprise value by raising profitability through cutting trade costs. In times of high economic policy uncertainty, vertical integration enhances internal collaboration through information superiority [27]. Compared to the mid-end manufacturing industry, highend manufacturing is more significant in terms of vertical integration generated by economic policy uncertainty. Thus, vertical integration could be a channel of economic policy uncertainty affecting manufacturing structural upgrading.

Economic policy uncertainty could also accelerate manufacturing structural upgrade by facilitating service transformation. Increasing customer coherence is crucial for sustainable business in times of high economic policy uncertainty. Clients demand differentiation of products in the modern economic environment, as homogenous products are unappealing. Thus, companies are forced to undertake service transformation to meet customer demands. Meanwhile, service transformation of enterprises could appeal to more clients and promote overall product quality, resulting in an increase in the firm's value. In the high-end industry, because of the abundance of techniques and devices, along with the fact of customers' heterogeneous demand, the stimulating effect of service transformation is more profound when faced with high economic policy uncertainty. Unlike the mid-end industry, the high-end industry tends to undertake service transformation. As a result, economic policy uncertainty could boost manufacturing structural upgrading through service transformation. Thus, we propose the following.

3.2. H1b. A positive correlation could be found between economic policy uncertainty and manufacturing structural upgrading, given strategy implementation of vertical integration and service transformation.

\section{Methodology and Data}

4.1. Methodologies. To examine the effect of economic policy uncertainty on manufacturing structural upgrading, we established the following statistical model:

$$
\mathrm{INDH}_{\mathrm{it}}=\alpha_{0}+\alpha_{1} \mathrm{EPU}_{\mathrm{it}}+\beta X_{\mathrm{it}}+\mu_{i}+\lambda_{t}+\varepsilon_{\mathrm{it}},
$$

where $i$ is province, and $t$ is the time. INDH is manufacturing structural upgrading. Following existing research, we measure INDH as the ratio of output of the high-end industry to output of the mid-end industry, reflecting the integration of the manufacturing industry [28]. High-end industry includes the manufacturing of raw chemical materials and products; pharmaceutical drugs; chemical fibers; machinery; specialized equipment; transport equipment; electrical machinery and equipment; electronics and communication equipment; instrumentation, cultural, and office machinery. Mid-end industry includes petroleum processing and coking; rubber and plastic products; nonmetallic mineral products; ferrous metal smelting and rolling processing; non-ferrous metal smelting and rolling processing; and manufacture of metal products. EPU is the core independent variable; we use the economic policy uncertainty index of Baker et al. [6] to measure Chinese economic policy uncertainty. This indicator is renewed monthly to match 
other variables and we transformed this monthly data to annual through the weighting method. To better interpret the estimate of the coefficient, we transformed the annual data into a percentage before applying it to the model. In terms of the stability test, we adopted the mean of the economic policy uncertainty index as a replacement indicator. $X_{\text {it }}$ is a vector of control variables. Following the existing research $[29,30]$, we choose the following variables as control variables: the ratio of foreign investment to total fixed investment (FDI), the logarithm of per capita GDP (PGDP), the ratio of the total value of China's imports and exports to GDP (OPNE), the ratio of gross output in nonstate-owned companies to gross output of all companies (MARKET), patents owned per millage (INNO), and the ratio of fiscal expenditure to GDP (FISC). We controlled for a number of fixed effects: $\mu_{i}$ and $\lambda_{t}$ are the fixed effects for province and year. $\varepsilon_{i t}$ is an error term and is assumed to be independent and identically distributed.

We chose the panel quantile regression model with a fixed effect to evaluate the conditional heterogeneity of the effect of EPU on manufacturing structural upgrading. Quantile regression can overcome the shortcomings of conditional mean regression [31-34]. The quantile regression model with a fixed effect was developed as follows:

$$
\mathrm{Q}_{\mathrm{INDH}_{\mathrm{it}}}\left(\tau_{k} \mid \mu_{i}, \mathrm{EPU}, X_{\mathrm{it}}\right)=\alpha_{1 \tau} \mathrm{EPU}+\beta_{\tau} X_{\mathrm{it}}+\mu_{i}+\varepsilon_{\mathrm{it}},
$$

where $Q_{\mathrm{INDH}_{\mathrm{it}}}\left(\tau_{k} \mid \mu_{i}, \mathrm{EPU}, X_{i t}\right)$ is the $\tau$-th conditional quantile of $\tau$-th. $\alpha_{1 \tau}$ is the estimated coefficients at quantile $\tau$ , representing the heterogeneity of the effect at different levels of manufacturing structural upgrading. $\mu_{i}$ denotes the unobserved province fixed effects, and $X_{\text {it }}$ is a vector of control variables. Owing to fixed effect panel quantile regression including a number of fixed effects $\left(\mu_{i}\right)$ which is susceptible to the incidental parameters problem, it is hard to eliminate unobserved fixed effects by standard methods. To solve the problem, a proper method was proposed by Koenker [31] called shrinkage method. Penalty term is introduced to improve the estimation quality. The parameters are estimated as follows:

$$
\left(\widehat{\alpha}_{1 \tau}\left(\tau_{k}, \gamma\right), \widehat{\beta}_{\tau}\left(\tau_{k}, \gamma\right),\left\{\mu_{i}(\gamma)\right\}_{i=1}^{N}\right)=\arg \min \sum_{k=1}^{K} \sum_{t=1}^{T} \sum_{n=1}^{N} w_{k} \rho_{\tau_{k}}\left(\mathrm{INDH}_{\mathrm{it}}-\mu_{i}-\alpha_{1 \tau} \mathrm{EPU}_{t}-\beta_{\tau} X_{i t}\right)+\gamma \sum_{i=1}^{N}\left|\alpha_{i}\right| .
$$

Among them, $\rho_{\tau_{k}}$ is the quantile loss function, and $w_{k}$ is the weight for the $k$-th quantile, controlling the contribution of the $k$-th quantile to the estimation. This paper uses equally weighted quantiles $w_{k}=1 / k$ [35]. $\gamma$ is the turning parameter which can improve the accuracy of the estimate of $\alpha_{1 \tau}$ and $\beta_{\tau}$ by diminishing the individual effects to zero. As we can know, if the coefficient of penalty term $\gamma=0$, a usual fixed effect estimator can be got. When $\gamma$ increases to infinity, a model estimate with on individual effects is obtained. Following the previous work $[36,37]$, we set $\gamma=1$ in this paper.

4.2. Data. We selected 30 province-level panel data pieces with a time span from 1997 to 2018 as samples for benchmark regression. Our data on gross industry output, gross industry sales output, and stock data are mainly from the China Statistical Yearbook and Yearbook of Chinese Industry. Missing data were recovered from the Tai'an database. We acquired EPU data from http://www. policyuncertainty.com/scmp_monthly.html. The data of the innovation variable originates from the State Intellectual Property Office of China and the China Statistical Yearbook. The rest of the data were extracted from the China Statistical Yearbook. Table 1 concludes the summary statistics for all variables during the sample period.

From Table 1, we can find that the mean value of INDH is 1.4721 , and its maximum value is 6.2952 , indicating that there may be significant differences in industrial structure of manufacturing among provinces. The mean value of EPU is 0.9120 , and its maximum value is 1.7290 , showing that uncertainty in economic policy has experienced great variation during the sample period. The statistical characteristics of other variables are within the normal range.

\section{Empirical Results}

5.1. Baseline Results. Table 2 examines the effect of economic policy uncertainty on manufacturing structural upgrading. The estimated coefficient of interest is that for EPU. Column 1 estimates the basic impact of economic policy uncertainty on manufacturing structural upgrading while controlling for the fixed effects of province and year. The coefficient of EPU is 0.096 and significantly positive, indicating that the manufacturing structure will be upgraded in times of high economic policy uncertainty. In column 2, we used the arithmetic mean method to transform the monthly data to annual and find that the coefficient of EPU decreased only slightly to 0.075 and remained positively significant. We investigated the robustness of this effect in columns 3 and 4. Specifically, in column 3, we introduced the U.S. economic policy uncertainty index as an instrumental variable, and used a two-stage estimation method to estimate the coefficient. The reason for selecting US economic policy uncertainty index as an instrumental variable lies in that United States is the world's largest power, and fluctuations in its economic policies often affect other countries, while China's economic policy uncertainty has little impact on the US. In column 4, we used province-level data from 2000 to 2018 to perform regression analysis. The coefficients of EPU retained similar patterns and were significantly positive at the $5 \%$ level, consistent with the above conclusion. All our results show that the manufacturing structure would improve during periods of high economic policy uncertainty. 
TABLE 1: Descriptive statistics of variables.

\begin{tabular}{|c|c|c|c|c|c|c|}
\hline Variable & Name & Mean & $\mathrm{Sd}$ & Min & P50 & Max \\
\hline INDH & Output of the high-end industry/output of the mid-end industry & 1.4721 & 1.0577 & 0.1533 & 1.1795 & 6.2952 \\
\hline EPU & Economic policy uncertainty & 0.9120 & 0.3379 & 0.4408 & 0.7915 & 1.7290 \\
\hline FDI & Foreign investment/total fixed investment & 0.0784 & 0.0810 & 0.0011 & 0.0495 & 0.4237 \\
\hline PGDP & The logarithm of per capital GDP & 9.2693 & 0.6840 & 7.6470 & 9.2373 & 10.9820 \\
\hline OPEN & Total value of China's import and export/GDP & 0.3110 & 0.3993 & 0.0320 & 0.1217 & 1.7215 \\
\hline MARKET & Output of non-state-owned companies/output of all companies & 0.4988 & 0.2108 & 0.1012 & 0.4835 & 0.9059 \\
\hline INNO & Patents owned per millage & 0.0255 & 0.0685 & 0 & 0.0058 & 0.7865 \\
\hline FISC & Fiscal expenditure/GDP & 0.1598 & 0.0726 & 0.0478 & 0.1444 & 0.5792 \\
\hline
\end{tabular}

TABLE 2: Baseline results.

\begin{tabular}{lcccc}
\hline Variables & $(1)$ & $(2)$ & $(3)$ & $(4)$ \\
\hline EPU & $0.0955^{* *}(2.6466)$ & $0.0748^{*}(1.8782)$ & $0.2674^{* * *}(2.8784)$ & $0.0369^{*}(1.9348)$ \\
FDI & $1.5023(1.0230)$ & $1.5000(1.0206)$ & $1.4919(1.0508)$ & $2.5390^{*}(1.7046)$ \\
PGDP & $-0.3662(-0.6163)$ & $-0.3859(-0.6474)$ & $-0.3383(-0.5945)$ & $-0.0075(-1.3112)$ \\
OPEN & $0.8137^{* * *}(3.1231)$ & $0.8174^{* * *}(3.0918)$ & $0.8698^{* * *}(3.2195)$ & $0.7463^{* * *}(3.0092)$ \\
MARKET & $-0.6146(-1.0599)$ & $-0.6138(-1.0584)$ & $-0.6049(-1.0764)$ & $-0.5650(-1.0906)$ \\
INNO & $2.1992^{* * *}(3.9390)$ & $2.1588^{* * *}(3.7720)$ & $2.1596^{* * *}(3.8946)$ & $2.7876^{* * *}(15.0392)$ \\
FISC & $-0.2341(-0.1238)$ & $-0.2557(-0.1343)$ & $-0.5058(-0.2674)$ & $0.1025(0.0560)$ \\
Time & $0.0122(0.2548)$ & $0.0152(0.3151)$ & $0.0034(0.0746)$ & $-0.0207(-0.7172)$ \\
Constant & $-19.7368(-0.2167)$ & $-25.4992(-0.2784)$ & - & $42.7122(0.7437)$ \\
$N$ & 660 & 660 & 660 & 570 \\
Adj $R$-squared & 0.8738 & 0.8737 & 0.2251 & 0.8695 \\
Province fixed effect & Yes & Yes & Yes & Yes \\
Year fixed effect & Yes & Yes & Yes & Yes \\
\hline
\end{tabular}

Notes: $t$ values calculated by standard errors clustered at the province-level are reported in parentheses. ${ }^{* * *}$, ${ }^{* *}$, and ${ }^{*}$ indicate significance at the $1 \%, 5 \%$, and $10 \%$ levels, respectively.

5.2. Heterogeneity Analysis. The panel quantile regression method can outmatch traditional ordinary least squares (OLS) regression by providing a more detailed description and more stable results. Hence, we applied the panel quantile regression method to acquire the results from different quantiles. The results are displayed in Table 3.

Table 3 shows that the effect of EPU on the manufacturing industry structure is large in provinces at an advanced stage of manufacturing industry structure, as the coefficient of the upper quantile $(\tau=0.6,0.7,0.8,0.9)$ was significantly positive, and most of the other quantiles were not significant except for $\tau=0.3$. The result is consistent with experiential studies. A possible explanation is that, at advanced stages of manufacturing industry structure, the scale of high-end technology manufacturing would be large, which would be highly attractive to skilled employees and high-end services. In times of economic policy uncertainty, superior resources will be more concentrated to avoid risks, and provinces entering an advanced stage of manufacturing industry structure have a competitive advantage of attracting superior resources.

5.3. Potential Mechanisms. Thus far, we have shown that economic policy uncertainty significantly promotes structural upgrading in manufacturing. In this subsection, we investigate the underlying mechanisms behind our findings. According to the previous analysis, economic policy uncertainty can affect manufacturing structure through corporate innovation, the proportion of skilled labor, vertical integration, and service transformation.

To examine the above mechanisms, we chose mid-end and high-end manufacturing listed companies as our sample from 2012 to 2018 under the limitation of availability and quality. Our data are obtained from the Wind database and the China Statistical Yearbook. We constructed four variables to measure different mechanisms. Specifically, we introduced PATENT as a proxy for the effect of economic policy uncertainty on enterprise technology innovation, defined as the number of innovation patents authorized. Then, we introduced SKILL to verify the mechanism of the proportion of skilled labor, measured by the ratio of employees with a high school diploma to the total number of employees. Next, we constructed a VAS to investigate the impact of economic policy uncertainty on vertical integration, defined as the ratio of added value in different industrial chains to sales value. Finally, we constructed SERVICE to investigate the mechanism of service transformation, measured by the ratio of service revenue to total revenue.

Based on the above four measures, we constructed the following model:

$$
\begin{aligned}
Y_{\mathrm{ijt}}= & \alpha_{0}+\alpha_{1} \mathrm{HIGH}_{i} \times \mathrm{EPU}_{\mathrm{jt}}+\alpha_{2} \mathrm{EPU}_{\mathrm{jt}}+\beta X_{i j t}+\lambda_{t} \\
& +\mu_{i}+\delta_{j}+\varepsilon_{\mathrm{it}},
\end{aligned}
$$

where $i$ is the firm, $j$ is the province's location, $t$ is the time, and $\mathrm{HIGH}_{i}$ is a dummy variable that equals one if firm $i$ 
TABLE 3: Results of panel quantile regression model.

\begin{tabular}{|c|c|c|c|c|c|c|c|c|c|}
\hline Variables & (1) Q10 & (2) Q20 & (3) Q30 & (4) Q40 & (5) Q50 & (6) Q60 & (7) Q70 & (8) Q80 & (9) Q90 \\
\hline EPU & $0.336(1.49)$ & $\begin{array}{l}-0.035 \\
(-0.46)\end{array}$ & $\begin{array}{c}0.253^{* *} \\
(2.11)\end{array}$ & $\begin{array}{l}-0.038 \\
(-1.62)\end{array}$ & $0.020(0.72)$ & $\begin{array}{c}0.175^{* * *} \\
(19.31)\end{array}$ & $\begin{array}{c}0.055^{* * *} \\
(70.29)\end{array}$ & $\begin{array}{c}0.102^{* * *} \\
(2.51)\end{array}$ & $\begin{array}{c}0.262^{* * *} \\
(10.08)\end{array}$ \\
\hline FDI & $\begin{array}{c}1.439^{* * *} \\
(8.85)\end{array}$ & $\begin{array}{c}2.537^{* * *} \\
(9.50)\end{array}$ & $\begin{array}{c}2.127^{* * *} \\
(6.20)\end{array}$ & $\begin{array}{c}1.674^{* * *} \\
(13.84)\end{array}$ & $\begin{array}{c}1.925^{* * *} \\
(9.62)\end{array}$ & $\begin{array}{c}2.828^{* * *} \\
(21.24)\end{array}$ & $\begin{array}{l}2.592^{* * *} \\
(329.99)\end{array}$ & $\begin{array}{c}4.847^{* * *} \\
(6.38)\end{array}$ & $\begin{array}{c}4.329^{* * *} \\
(29.03)\end{array}$ \\
\hline PGDP & $\begin{array}{c}-0.074^{* * *} \\
(-3.79)\end{array}$ & $\begin{array}{c}-0.022^{*} \\
(-1.94)\end{array}$ & $\begin{array}{l}-0.009 \\
(-0.59)\end{array}$ & $0.009(0.98)$ & $0.012(0.78)$ & $\begin{array}{c}0.019^{* * *} \\
(8.63)\end{array}$ & $\begin{array}{c}-0.009^{* * *} \\
(-150.02)\end{array}$ & $\begin{array}{c}0.008 \\
(0.22)\end{array}$ & $\begin{array}{c}0.039^{* * *} \\
(10.82)\end{array}$ \\
\hline OPEN & $\begin{array}{c}1.012^{* * *} \\
(37.78)\end{array}$ & $\begin{array}{c}0.816^{* * *} \\
(24.87)\end{array}$ & $\begin{array}{c}0.854^{* * * *} \\
(24.97)\end{array}$ & $\begin{array}{c}0.846^{* * *} \\
(29.82)\end{array}$ & $\begin{array}{c}0.738^{* * *} \\
(20.13)\end{array}$ & $\begin{array}{c}0.541^{* * *} \\
(42.27)\end{array}$ & $\begin{array}{l}0.514^{* * *} \\
(542.59)\end{array}$ & $\begin{array}{c}0.532^{* * *} \\
(3.81)\end{array}$ & $\begin{array}{c}0.341^{* * *} \\
(10.63)\end{array}$ \\
\hline MARKET & $\begin{array}{c}0.473^{* * *} \\
(8.99)\end{array}$ & $\begin{array}{c}0.477^{* * *} \\
(3.16)\end{array}$ & $\begin{array}{c}0.572^{* * *} \\
(5.86)\end{array}$ & $\begin{array}{c}0.539^{* * *} \\
(2.83)\end{array}$ & $\begin{array}{c}0.417^{* * *} \\
(2.85)\end{array}$ & $\begin{array}{l}0.447^{* * *} \\
(17.352)\end{array}$ & $\begin{array}{l}0.708^{* * *} \\
(275.61)\end{array}$ & $\begin{array}{c}0.499^{*} \\
(1.82)\end{array}$ & $\begin{array}{c}-2.702^{* * *} \\
(-110.14)\end{array}$ \\
\hline INNO & $\begin{array}{c}2.532^{* * *} \\
(19.35)\end{array}$ & $\begin{array}{c}2.899^{* * *} \\
(10.95)\end{array}$ & $\begin{array}{c}2.912^{* * *} \\
(43.17)\end{array}$ & $\begin{array}{c}3.079^{* * *} \\
(145.04)\end{array}$ & $\begin{array}{c}3.059^{* * *} \\
(55.40)\end{array}$ & $\begin{array}{c}3.048^{* * *} \\
(215.60)\end{array}$ & $\begin{array}{l}3.166^{* * *} \\
(210.45)\end{array}$ & $\begin{array}{c}3.185^{* * *} \\
(6.65)\end{array}$ & $\begin{array}{c}2.258^{* * *} \\
(26.78)\end{array}$ \\
\hline FISC & $\begin{array}{c}-0.843^{*} \\
(-1.86)\end{array}$ & $\begin{array}{l}-0.441 \\
(-1.03)\end{array}$ & $\begin{array}{l}-0.166 \\
(-0.46)\end{array}$ & $\begin{array}{l}-0.121 \\
(-0.29)\end{array}$ & $\begin{array}{c}-1.171^{* * *} \\
(-5.17)\end{array}$ & $\begin{array}{c}-1.529^{* * *} \\
(-40.85)\end{array}$ & $\begin{array}{c}-1.5500^{* * * *} \\
(-230.00)\end{array}$ & $\begin{array}{l}-0.882 \\
(-1.45)\end{array}$ & $\begin{array}{c}-4.552^{* * *} \\
(-38.84)\end{array}$ \\
\hline Time & $\begin{array}{c}-0.073^{* *} \\
(-2.44)\end{array}$ & $\begin{array}{c}-0.027^{* * * *} \\
(-13.30)\end{array}$ & $\begin{array}{c}-0.052^{* * *} \\
(-3.24)\end{array}$ & $\begin{array}{c}-0.026^{* * * *} \\
(-4.82)\end{array}$ & $\begin{array}{c}-0.031^{* * *} \\
(-9.80)\end{array}$ & $\begin{array}{c}-0.032^{* * *} \\
(-70.94)\end{array}$ & $\begin{array}{l}-0.032^{* * *} \\
(-210.25)\end{array}$ & $\begin{array}{c}-0.014^{* *} \\
(-2.53)\end{array}$ & $0.003(0.31)$ \\
\hline$N$ & 660 & 660 & 660 & 660 & 660 & 660 & 660 & 660 & 660 \\
\hline
\end{tabular}

Notes: $t$ values are reported in parentheses. ${ }^{* * *},{ }^{* *}$, and ${ }^{*}$ indicate significance at the $1 \%, 5 \%$, and $10 \%$ levels, respectively.

belongs to the high-end manufacturing industry. $X_{\mathrm{ijt}}$ is a vector of the control variables: (1) ratio of equity to debt (ELR), measured by the ratio of owners' equity to total liabilities; (2) return on equity (ROE), measured by the ratio of net profit to balance of shareholders' equity; (3) rate of overhead expenses (FEE), measured by the ratio of administrative expenses to operating income; (4) current ratio (CR), measured by the ratio of current assets to current liabilities; (5) state-owned enterprises (SOE), which equals one for state-owned enterprises and zero for non-stateowned enterprises; (6) firm size (SIZE), defined as the log form of total assets. We control for a number of fixed effects: $\lambda_{t}, \mu_{i}$, and $\delta_{j}$ are the fixed effects for year, firm, and province, respectively.

Table 4 presents the estimated results of Model (3). Column 1 shows that economic policy uncertainty has a significant negative impact on a firm's technological innovation. Moreover, the coefficient of $\mathrm{HIGH}_{i} \times \mathrm{EPU}_{\mathrm{jt}}$ is -0.043 and is significantly negative, indicating that, compared to the mid-end manufacturing industry, the high-end manufacturing industry tends to postpone innovative activities during periods of economic policy uncertainty. Therefore, economic policy uncertainty hinders structural upgrading in manufacturing through postponing of innovation activities.

Owing to higher education costs and greater hierarchy in terms of employment position, it is common for skilled workers to have higher employment costs; hence, in times of high economic policy uncertainty, companies tend to reduce employment to have sufficient cash flow. We investigated whether economic policy uncertainty has any impact on the structure of employment, and the results are displayed in column 2. Column 2 indicates that economic policy uncertainty significantly reduced the ratio of skilled labor. The coefficient of $\mathrm{HIGH}_{i} \times \mathrm{EPU}_{\mathrm{jt}}$ is -0.007 and is significantly negative, which means that, compared to the mid-end manufacturing industry, the high-end industry tends to reduce skilled labor during the period of high economic policy uncertainty. Based on the above analysis, we conclude that economic policy uncertainty hinders structural upgrading in manufacturing by suppressing the ratio of skilled labor.

Column 3 displays the effect of economic policy uncertainty on service transformation. The results show that economic policy uncertainty significantly promotes firms' service transformation. The coefficient of $\mathrm{HIGH}_{i} \times \mathrm{EPU}_{\mathrm{jt}}$ is 0.008 , suggesting that the high-end manufacturing industry tends to undertake service transformation to increase corporate value. Therefore, service transformation plays an important role in the facilitating effect of economic policy uncertainty on manufacturing industry structural upgrades. Despite economic policy uncertainty hindering technology innovation, it raises corporate value through service transformation and increased client coherency.

To clarify how economic policy uncertainty influences the corporate organization mode, we further investigated how economic policy uncertainty affects corporate vertical integration. Column 4 displays the results. The results of column 4 indicate that economic policy uncertainty accelerated the transformation to vertical integration. The coefficient of $\mathrm{HIGH}_{i} \times \mathrm{EPU}_{\mathrm{jt}}$ is 0.029 and is significantly positive, suggesting that the high-end manufacturing industry tends to adopt a vertical integration method during periods of high economic policy uncertainty. A possible explanation could be that the high-end industry tends to explore new technology while maintaining a stabilized supply to increase competitiveness, as it has a higher technique density than the mid-end industry. Another explanation could be the capital-intensive feature of the highend industry. Compared to the labor-intensive mid-end industry, assets are more specialized here, and the vertical integration effect is more significant than in the mid-end industry during the period of economic policy uncertainty. Overall, economic policy uncertainty has a stimulating effect on vertical integration. Moreover, the integration is significantly and positively related to corporate output increase and facilitates structural upgrading in manufacturing. 
TABLE 4: Results of mechanism analysis.

\begin{tabular}{lcccc}
\hline Variables & (1) PATENT & (2) SKILL & (3) SERVICE & $(4)$ VAS \\
\hline HIGH $\times$ EPU & $-0.043^{*}(-1.812)$ & $-0.007^{* *}(-2.381)$ & $0.028^{* *}(2.363)$ & $0.029^{* * *}(4.689)$ \\
EPU & $-0.039^{*}(-1.791)$ & $-0.018^{* * *}(-6.172)$ & $0.003^{*}(1.899)$ & $0.037^{* * *}(6.2876)$ \\
ELR & $-0.004(-0.320)$ & $0.0003(0.186)$ & $-0.003(-1.226)$ & $0.012(1.566)$ \\
ROE & $0.281^{* *}(2.509)$ & $0.051^{* * *}(3.249)$ & $0.016(0.707)$ & $-0.101^{* *}(-2.546)$ \\
FEE & $0.156(0.445)$ & $0.127^{* * *}(2.585)$ & $-0.039(-0.465)$ & $0.540^{* * *}(3.076)$ \\
CR & $0.018(1.439)$ & $-0.0003(-0.156)$ & $0.0003(0.131)$ & $-0.002(-0.250)$ \\
SOE & $-0.0004(-0.0032)$ & $0.0145(1.0899)$ & $-0.0067(-0.4313)$ & $0.0007(0.0140)$ \\
SIZE & $0.2242^{* * *}(5.9310)$ & $-0.0459^{* * *}(-6.4277)$ & $0.0207^{* *}(2.3843)$ & $-0.0080(-0.7801)$ \\
Constant & $-3.6577(-0.0827)$ & $-42.0740^{* * *}(-6.9147)$ & $-120.012^{* * *}(-6.1156)$ & $14.5573(1.3224)$ \\
$N$ & 10148 & 9890 & 10148 & 5873 \\
Adj $R$-squared & 0.7570 & 0.8204 & 0.9718 & 0.4687 \\
Province fixed effect & Yes & Yes & Yes & Yes \\
Firm fixed effect & Yes & Yes & Yes & Yes \\
Year fixed effect & Yes & Yes & Yes \\
\hline
\end{tabular}

\section{Conclusions}

We investigated the impact of economic policy uncertainty on manufacturing structural upgrading using firm-level and province-level panel data from 1997 to 2018. Furthermore, we analysed the effect mechanism and heterogeneity. The empirical results suggest that economic policy uncertainty has a positive impact on structural upgrading in manufacturing, and the effect is more profound in regions at advanced stages of manufacturing structure. The mechanism test implies that economic policy uncertainty affects the structural upgrading by facilitating service transformation and vertical integration.

The results are unexpected at first glance, as they are unique in most of the studies. A possible explanation is our sample selection, as only mid-end and high-end manufacturing industries were included. We have performed a detailed investigation of the influence path as well as stability tests; the results are both plausible and reasonable.

Our research has significant policy implications. First, the government should focus on optimizing the business environment and attracting skilled labor to amplify the output expansion effect of the high-end industry. Meanwhile, local governments should increase support for enterprise service transformation to navigate companies undertaking service transformation at a high level of economic policy uncertainty. Second, the government must focus not only on the survival and development of enterprises, but also on the exit mechanism of enterprises when distributing administrative resources in order to increase the gross production rate. Vertical integration and the expansion margins of province-level investment could effectively offset the loss caused by economic policy uncertainty. It is also beneficial to market redistribution, increasing competitiveness, and ultimately facilitating local economic growth as well as the employment rate. Thus, the government should provide support for cross-province investment to seize the opportunity to develop.

\section{Data Availability}

The data used to support the findings of this study are available from the corresponding author request.

\section{Conflicts of Interest}

The authors declare that they have no conflicts of interest.

\section{Acknowledgments}

This research was supported by National Natural Science Foundation of China (grant no. 71774053).

\section{References}

[1] K. Zhou and Y. Li, "Carbon finance and carbon market in China: progress and challenges," Journal of Cleaner Production, vol. 214, pp. 536-549, 2019.

[2] Z. Zhang and M. Li, "Modelling green energy development based on sustainable economic growth in China," Sustainability, vol. 12, no. 4, Article ID 1368, 2020.

[3] W.-Q. Hu, T. Jin, and Y. Liu, "Effects of environmental regulation on the upgrading of Chinese manufacturing industry," Environmental Science and Pollution Research, vol. 26, no. 26, pp. 27087-27099, 2019.

[4] S. Anwar and S. Sun, "Foreign direct investment and export quality upgrading in China's manufacturing sector," International Review of Economics and Finance, vol. 54, pp. 289298, 2018

[5] Z. Xie, G. Zang, and F. Wu, "On the relationship between innovation activity and manufacturing upgrading of emerging countries: evidence from China," Sustainability, vol. 11, no. 5, Article ID 1309, 2019.

[6] S. R. Baker, N. Bloom, and S. J. Davis, "Measuring economic policy uncertainty*," Quarterly Journal of Economics, vol. 131, no. 4, pp. 1593-1636, 2016.

[7] V. Colombo, "Economic policy uncertainty in the US: does it matter for the Euro area?," Economics Letters, vol. 121, no. 1, pp. 39-42, 2013.

[8] B. Born and J. Pfeifer, "Policy risk and the business cycle," Journal of Monetary Economics, vol. 68, pp. 68-85, 2014.

[9] G. Caggiano, E. Castelnuovo, and J. M. Figueres, "Economic policy uncertainty and unemployment in the United States: a nonlinear approach," Economics Letters, vol. 151, pp. 31-34, 2017.

[10] D. Zhang, L. Lei, Q. Ji, and A. M. Kutan, "Economic policy uncertainty in the US and China and their impact on the global markets," Economic Modelling, vol. 79, pp. 47-56, 2019. 
[11] H. Smit, E. Pennings, and S. van Bekkum, "Real options and institutions," Journal of International Business Studies, vol. 48, no. 5, pp. 620-644, 2017.

[12] D. Gabauer and R. Gupta, "On the transmission mechanism of country-specific and international economic uncertainty spillovers: evidence from a TVP-VAR connectedness decomposition approach," Economics Letters, vol. 171, pp. 6371, 2018.

[13] S. Leduc and Z. Liu, "Uncertainty shocks are aggregate demand shocks," Journal of Monetary Economics, vol. 82, pp. 20-35, 2016.

[14] H. Mumtaz and P. Surico, "Policy uncertainty and aggregate fluctuations," Journal of Applied Econometrics, vol. 33, no. 3, pp. 319-331, 2018.

[15] B. Julio and Y. Yook, "Political uncertainty and corporate investment cycles," The Journal of Finance, vol. 67, no. 1, pp. 45-83, 2012.

[16] H. Gulen and M. Ion, "Policy uncertainty and corporate investment," Review of Financial Studies, vol. 29, no. 3, pp. 523-564, 2016.

[17] N. L. Stokey, "Wait-and-see: investment options under policy uncertainty," Review of Economic Dynamics, vol. 21, pp. 246-265, 2016.

[18] Z. Xu, "Economic policy uncertainty, cost of capital, and corporate innovation," Journal of Banking and Finance, vol. 111, Article ID 105698, 2020.

[19] Ľ. Pástor and P. Veronesi, "Political uncertainty and risk premia," Journal of Financial Economics, vol. 110, no. 3, pp. 520-545, 2013.

[20] J. Brogaard and A. Detzel, "The asset-pricing implications of government economic policy uncertainty," Management Science, vol. 61, no. 1, pp. 3-18, 2015.

[21] G. Herrigel, V. Wittke, and U. Voskamp, "The process of Chinese manufacturing upgrading: transitioning fromUnilateraltoRecursive mutual LearningRelations," Global Strategy Journal, vol. 3, no. 1, pp. 109-125, 2013.

[22] W. Kang, K. Lee, and R. A. Ratti, "Economic policy uncertainty and firm-level investment," Journal of Macroeconomics, vol. 39, pp. 42-53, 2014.

[23] B. S. Bernanke, "Irreversibility, uncertainty, and cyclical investment," Quarterly Journal of Economics, vol. 98, no. 1, pp. 85-106, 1983.

[24] A. K. Dixit, R. K. Dixit, and R. S. Pindyck, Investment under Uncertainty, pp. 103-105, Princeton University Press, Princeton, NJ, USA, 1994.

[25] Y. Huang and P. Luk, "Measuring economic policy uncertainty in China," China Economic Review, vol. 59, p. 42, Article ID 101367, 2020.

[26] M. Gervais, I. Livshits, and C. Meh, "Uncertainty and the specificity of human capital," Journal of Economic Theory, vol. 143, no. 1, pp. 469-498, 2008.

[27] G. P. Pisano, “The governance of innovation: vertical integration and collaborative arrangements in the biotechnology industry," Research Policy, vol. 20, no. 3, pp. 237-249, 1991.

[28] S. Tejani and W. Milberg, "Global defeminization? Industrial upgrading and manufacturing employment in developing countries," Feminist Economics, vol. 22, no. 2, pp. 24-54, 2016.

[29] Z. Li, S. Shao, X. Shi, Y. Sun, and X. Zhang, "Structural transformation of manufacturing, natural resource dependence, and carbon emissions reduction: evidence of a threshold effect from China," Journal of Cleaner Production, vol. 206, pp. 920-927, 2019.
[30] S. Tejani and D. Kucera, "Defeminization, structural transformation and technological upgrading in manufacturing," Development and Change, vol. 52, no. 3, pp. 533-573, 2021.

[31] R. Koenker, "Quantile regression for longitudinal data," Journal of Multivariate Analysis, vol. 91, no. 1, pp. 74-89, 2004.

[32] C. Lamarche, "Measuring the incentives to learn in Colombia using new quantile regression approaches," Journal of Development Economics, vol. 96, no. 2, pp. 278-288, 2011.

[33] M. Binder and A. Coad, "From Average Joe's happiness to Miserable Jane and Cheerful John: using quantile regressions to analyze the full subjective well-being distribution," Journal of Economic Behavior \& Organization, vol. 79, no. 3, pp. 275-290, 2011.

[34] I. A. Canay, "A simple approach to quantile regression for panel data," The Econometrics Journal, vol. 14, no. 3, pp. 368-386, 2011.

[35] C. Lamarche, "Robust penalized quantile regression estimation for panel data," Journal of Econometrics, vol. 157, no. 2, pp. 396-408, 2010.

[36] O. Damette and P. Delacote, "On the economic factors of deforestation: what can we learn from quantile analysis?" Economic Modelling, vol. 29, no. 6, pp. 2427-2434, 2012.

[37] H. Zhu, H. Xia, Y. Guo, and C. Peng, "The heterogeneous effects of urbanization and income inequality on $\mathrm{CO} 2$ emissions in BRICS economies: evidence from panel quantile regression," Environmental Science and Pollution Research, vol. 25, no. 17, pp. 17176-17193, 2018. 